\title{
Unil
}

UNIL | Université de Lausanne

Unicentre

$\mathrm{CH}-1015$ Lausanne

http://serval.unil.ch

Year : 2018

\section{Level of readiness of chronic pain patients to practise active self-care}

\author{
Scala Emmanuelle
}

Scala Emmanuelle, 2018, Level of readiness of chronic pain patients to practise active self-care

Originally published at : Thesis, University of Lausanne

Posted at the University of Lausanne Open Archive http://serval.unil.ch

Document URN : urn:nbn:ch:serval-BIB_4157D7C6FCC08

\section{Droits d'auteur}

L'Université de Lausanne attire expressément l'attention des utilisateurs sur le fait que tous les documents publiés dans l'Archive SERVAL sont protégés par le droit d'auteur, conformément à la loi fédérale sur le droit d'auteur et les droits voisins (LDA). A ce titre, il est indispensable d'obtenir le consentement préalable de l'auteur et/ou de l'éditeur avant toute utilisation d'une oeuvre ou d'une partie d'une oeuvre ne relevant pas d'une utilisation à des fins personnelles au sens de la LDA (art. 19, al. 1 lettre a). A défaut, tout contrevenant s'expose aux sanctions prévues par cette loi. Nous déclinons toute responsabilité en la matière.

\section{Copyright}

The University of Lausanne expressly draws the attention of users to the fact that all documents published in the SERVAL Archive are protected by copyright in accordance with federal law on copyright and similar rights (LDA). Accordingly it is indispensable to obtain prior consent from the author and/or publisher before any use of a work or part of a work for purposes other than personal use within the meaning of LDA (art. 19, para. 1 letter a). Failure to do so will expose offenders to the sanctions laid down by this law. We accept no liability in this respect. 


\section{Unil}

UNIL | Université de Lausanne

\section{Ecole doctorale}

UNIVERSITE DE LAUSANNE - FACULTE DE BIOLOGIE ET DE MEDECINE

Département des services de chirurgie et d'anesthésiologie

Service d'anesthésiologie, Centre d'antalgie

Level of readiness of chronic pain patients to practise active self-care

THESE

préparée sous la direction de la Professeure Isabelle Décosterd

(avec la co-direction du Professeur Pierre-Yves Rodondi)

et présentée à la Faculté de biologie et de médecine de

I'Université de Lausanne pour l'obtention du grade de

DOCTEUR EN MEDECINE

par

Emmanuelle Scala

Médecin diplômée de la Confédération Suisse

Originaire de Carona (Tessin/Suisse) 


\section{Unil}

UNIL | Université de Lausanne

\section{Ecole doctorale}

UNIVERSITE DE LAUSANNE - FACULTE DE BIOLOGIE ET DE MEDECINE

Département des services de chirurgie et d'anesthésiologie

Service d'anesthésiologie, Centre d'antalgie

Level of readiness of chronic pain patients to practise active self-care

THESE

préparée sous la direction de la Professeure Isabelle Décosterd

(avec la co-direction du Professeur Pierre-Yves Rodondi)

et présentée à la Faculté de biologie et de médecine de

I'Université de Lausanne pour l'obtention du grade de

DOCTEUR EN MEDECINE

par

Emmanuelle Scala

Médecin diplômée de la Confédération Suisse

Originaire de Carona (Tessin/Suisse) 
UNIL | Université de Lausanne

Faculté de biologie

Ecole Doctorale

et de médecine

Doctorat en médecine

\section{Imprimatur}

Vu le rapport présenté par le jury d'examen, composé de

Directeur de thèse Madame la Professeure Pre Isabelle Decosterd

Co-Directeur de thèse Monsieur le Professeur Pierre-Yves Rodondi

Expert

Monsieur le Professeur Arnaud Chiolero

Vice-Directeur de

I'Ecole doctorale

Monsieur le Professeur John Prior

la Commission MD de l'Ecole doctorale autorise l'impression de la thèse de

\section{Madame Emmanuelle SCALA}

intitulée

Level of readiness of chronic pain patients to practise active selfcare

Lausanne, le 20 septembre 2018

pour Le Doyen

de la Faculté de Biologie et de Médecine

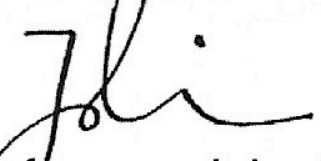

Monsieur le Professeur John Prior Vice-Directeur de l'Ecole doctorale 


\section{« Degré de préparation des patients atteints de douleur chronique à pratiquer des méthodes actives d'auto-soin »}

Le soulagement de la douleur chronique par les traitements pharmacologiques classiques reste limité. Diverses approches non pharmacologiques comme les méthodes actives d'auto-soin sont étudiées depuis une dizaine d'années et font l'objet de diverses publications. Ces méthodes peuvent être proposées aux patients douloureux chroniques mais nécessitent leur motivation. Notre objectif était de mesurer le niveau de préparation (LOR) à pratiquer des méthodes actives d'auto-soin chez les patients souffrant de douleur chronique.

Une enquête transversale quantitative mono-centrique a été menée auprès de tous les patients souffrant de douleur chronique suivis au Centre de la Douleur du Centre Hospitalier Universitaire Vaudois de juin 2013 à mars 2015, sous la forme d'un questionnaire qui a été envoyé à 1600 patients. Les données sociodémographiques, les caractéristiques de la douleur (y compris Chronic Pain Grade), la présence de symptômes anxieux ou dépressifs (Hospital Anxiety and Depression Scale HADS), les traitements déjà entrepris, et le degré de préparation à pratiquer diverses méthodes d'auto-soin ont été investigués. Une échelle visuelle et analogique a été créée afin d'évaluer le degré de préparation des patients avec la question suivante : « Si votre médecin vous le proposait, à quel point seriez-vous prêt(e) à utiliser les méthodes suivantes comme complément au traitement de votre douleur, sur une échelle de 0 à 10 , où 0 signifie «pas du tout prêt(e)» et 10 signifie «tout à fait prêt(e)»? ».[Ḷp]

Parmi les 1524 patients éligibles (ayant reçus le questionnaire), 639 (41,9\%) ont été inclus. La durée médiane de la douleur était de 8,5 ans (intervalle interquartile $=7,5$ ). Les patients ayant participé à l'étude étaient très handicapés par leur douleur, en effet, les deux tiers des patients $(63,7 \%)$ ont déclaré une incapacité élevée liée à la douleur et $64,6 \%$ avaient consommé des opioïdes au cours des six derniers mois. La plupart des patients ont déclaré un degré de préparation élevé $(44,1 \%)$ ou modéré $(24,6 \%)$ à pratiquer des méthodes actives d'auto-soin. L'analyse de régression multivariable multinomiale a montré que les facteurs indépendants associés à un degré de préparation élevé étaient un niveau de formation plus avancé ( $R R R=3,42$, intervalle de confiance à 95\% (IC): 1,90-6,13, p <0,001), la perte d'emploi en raison d'un problème médical (RRR = 2,92, IC 95\%: 1,30-6,56, $\mathrm{p}=0,009)$, l'utilisation de compléments alimentaires «contre la douleur» $(\mathrm{RRR}=2,77, \mathrm{IC} 95 \%: 1,52-5,04, \mathrm{p}=$ $0,001)$ et les caractéristiques neuropathiques de la douleur $(R R R=1,80, \mathrm{IC}$ à $95 \%: 1,40-3,12, p=0,036)$. L'âge avancé était un facteur prédisant un degré de préparation inférieur ( $R R R=0,97, \mathrm{IC}$ à 95\%: 0,94-0,99, $\mathrm{p}=0,039)$. La douleur chronique à long terme, l'invalidité sévère liée à la douleur et la présence d'un trouble de l'humeur n'étaient pas associés à un degré de préparation plus faible.

En conclusion, cette étude a permis de démontrer que la plupart des patients souffrant de douleur chronique, y compris ceux qui sont sévèrement atteints, se disent prêts à pratiquer des méthodes actives d'auto-soin. Ceci est une conclusion importante car contrairement aux croyances qu'un patient sévèrement atteint se tourne vers des méthodes passives de prise en charge, les patients douloureux chroniques sont toujours prêts à tenter des méthodes actives de traitement. 


\title{
Level of readiness of chronic pain patients to practise active self-care
}

\author{
E. Scala ${ }^{1,2}$, I. Decosterd ${ }^{1,2}$, M. Faouzi ${ }^{3}$, B. Burnand ${ }^{3}$, P.-Y. Rodondi ${ }^{3,4}$ \\ 1 Pain Center and Center for integrative and complementary medecine (CEMIC), Department of Anesthesiology, Lausanne University Hospital \\ (CHUV), Lausanne, Switzerland \\ 2 Faculty of Biology and Medicine (FBM), University of Lausanne (UNIL), Lausanne, Switzerland \\ 3 Institute of Social and Preventive Medicine, Lausanne University Hospital and Faculty of Biology and Medicine, University of Lausanne, \\ Lausanne, Switzerland \\ 4 Institute of Family Medicine, University of Fribourg, Fribourg, Switzerland
}

\section{Correspondence}

Emmanuelle Scala and Pierre-Yves Rodondi E-mails: Emmanuelle.Scala@chuv.ch; pierre-yves.rodondi@unifr.ch

\section{Funding sources}

This study was supported by a grant from the Swiss National Science Foundation (Special Program University Medicine 33CM30140339 to ID).

\section{Conflicts of interest}

The authors declare that they have no conflict of interests.

\section{Accepted for publication}

25 June 2018

doi:10.1002/ejp.1276

\begin{abstract}
Background: Given the limited alleviation of chronic pain with pharmacological treatments, various nonpharmacological and self-care approaches are often proposed that require patients' motivation.

Objective: To evaluate the level of readiness (LOR) to practise different types of active self-care among chronic pain patients.

Method: A quantitative cross-sectional survey was conducted among all chronic pain patients seeking care at the Pain Center of an academic hospital from June 2013 to March 2015. Sociodemographic data, pain characteristics, treatments and the LOR to practise active self-care were investigated.

Results: Among the 1524 eligible patients, 639 (41.9\%) were included. The median pain duration was 8.5 years (interquartile range $=7.5$ ). Twothirds $(63.7 \%)$ of the patients reported high pain-related disability, and $64.6 \%$ had used opioids during the previous six months. Most patients had a high $(44.1 \%)$ or moderate $(24.6 \%)$ LOR to practise active self-care. Multivariable multinomial regression analysis showed that independent factors associated with a high LOR were a higher level of education (relative risk ratio $(\mathrm{RRR})=3.42,95 \%$ confidence interval $(\mathrm{CI}): 1.90-6.13$, $p<0.001)$, unemployed status due to medical condition $(\mathrm{RRR}=2.92$, 95\% CI: $1.30-6.56, p=0.009)$, the use of dietary supplements 'against pain' (RRR $=2.77,95 \%$ CI: $1.52-5.04, p=0.001)$ and neuropathic pain characteristics $(\mathrm{RRR}=1.80,95 \% \mathrm{CI}: 1.40-3.12, p=0.036)$. Older age was a factor predicting a lower LOR $(\mathrm{RRR}=0.97,95 \%$ CI: 0.94-0.99, $p=0.039)$. Long-term chronic pain, severe pain-related disability and the presence of a mood disorder were not associated with a lower LOR.

Conclusion: Most chronic pain patients, including those severely affected, indicated their readiness to practise active self-care methods.

Significance: Most chronic pain patients, even those severely affected, appeared to be ready to practise active self-care therapies and we believe that further studies are needed to investigate their impact on pain and quality of life.
\end{abstract}

\section{Introduction}

Self-care strategies for pain management have been highlighted during the past decade. The prevalence of chronic pain is high (Breivik et al., 2006; Bouhassira

et al., 2008; Hauser et al., 2014), and the alleviation of chronic pain via pharmacological or interventional treatments is limited (MacFarlane et al., 1996; Elliott et al., 2002; Kurita et al., 2012; Delgado et al., 2014). 
Additionally, concerns about adverse events related to drug treatment (Turk et al., 2011; Edlund et al., 2014; Ekholm et al., 2014; Sutherland, 2014) are increasing. Thus, nonpharmacological options are suggested, including self-care (Blyth et al., 2005; Chou et al., 2007; Rosenquist Richard, 2010; Crawford et al., 2014b). Self-care is defined as therapies self-administered by patients 'to manage symptoms or consequences inherent in living with a chronic condition' (Barlow et al., 2002). This approach could 'empower patients to take control of their condition with the aim to improve quality-of-life outcome' (Boyers et al., 2013) and has the potential to provide more efficient and comprehensive chronic pain management (Crawford et al., 2014b).

In addition to being relatively safe (Crawford et al., 2014 b), active self-care 'was associated with decreased pain-related disability, distress, reliance on medication, use of formal health care' and 'better general health' (Blyth et al., 2005). Moreover, a recent metaanalytic review showed a small but robust effect of guided self-help on pain severity and disability in chronic pain patients (Liegl et al., 2016). For example, physical activity adapted to a patient's condition could decrease the prevalence of chronic low back pain (Heneweer et al., 2009), pain intensity and associated disability. It could also improve quality of life and physical capacity (Baena-Beato et al., 2013), particularly in osteoarthritis (Uthman et al., 2013), neuropathic pain (Dobson et al., 2014), chronic low back pain (Hayden et al., 2005) and fibromyalgia (Busch et al., 2007). Other methods include physically oriented therapies (e.g. acupressure, self-administered therapeutic medical massage), movement therapies (e.g. yoga, tai chi, qi gong), mind-body therapies (e.g. self-hypnosis, autogenic training, meditation/mindfulness, relaxation training, breathing exercises, imagery-guided therapy) and sensory art therapies (e.g. art therapy, dance therapy, music therapy) (Crawford et al., 2014a; Delgado et al., 2014).

While patients' preferences should be taken into consideration (Wong et al., 2017), it is unclear how motivated chronic pain patients are to implement different types of active self-care. Motivation has been described as an essential factor for self-management (Jensen et al., 2003, 2004; Habib et al., 2005), because it has been recognized to impact adherence and engagement in treatment (Jensen et al., 2003; Habib et al., 2005; Dorflinger et al., 2013), as well as patient success and satisfaction for self-care in chronic pain treatment (Shutty et al., 1990; Dorflinger et al., 2013). Engagement in self-management is also influenced by the patient-provider communication process, as provider can influence motivation enhancement (Frantsve and Kerns, 2007; Dorflinger et al., 2013).

The motivation for treatment is also associated with lower pain ratings (Shutty et al., 1990) and increased ratings of physical ability (Shutty et al., 1990). Motivation consists of multiple aspects, especially beliefs concerning the pain itself and the treatment (Marcus et al., 1992; Keller et al., 2001; Jensen et al., 2003; Rau et al., 2007). The level of motivation to change has been studied in the literature and has led to the transtheoretical model (Prochaska et al., 1992; Rollnick et al., 1992; Rau et al., 2007; Korcha et al., 2012). The level of readiness (LOR) is considered to correspond to a linearization of the different stages of the transtheoretical model [45] and is hypothesized to predict engagement in self-management behaviors' (Jensen et al., 2003), and in chronic pain treatment (Keller et al., 2001; Habib et al., 2005). It is used to evaluate patients' motivation in chronic pain treatment (Keller et al., 2001) or to adopt different health-related behaviours (Rau et al., 2007; Korcha et al., 2012), e.g. physical activity (Marcus et al., 1992; Falk and Anderson, 2013; Ardern et al., 2014).

The main objective of this study was to evaluate the LOR to practise active self-care methods when suggested by a physician and the associated factors among the chronic pain patients of a tertiary Pain Center. The secondary objectives were to evaluate the LOR for each active self-care method and to describe which methods the chronic pain patients had already tried.

\section{Methods}

\subsection{Design of the study}

A quantitative cross-sectional postal survey was conducted among the patients of an academic medical centre using a structured questionnaire after obtaining approval from the ethics committee of the Canton of Vaud (Ref. 185/15).

\subsection{Settings and sample calculation}

The study was conducted in Lausanne University Hospital, Switzerland. All patients above 18 years old seeking care at the Pain Center at least once between June 2013 and March 2015 were eligible to receive the questionnaire. Patients were included if they suffered from chronic pain lasting at least six months according to the International Association 
for the Study of Pain (IASP) (IASP, 1986) and if they were able to read French fluently. A lexicon (see Appendix S1) of the treatments mentioned in the questionnaire was also sent to the patients and a phone number was provided to the patients in case any questions needed clarifications during the filling of the questionnaire. A reminder was sent two weeks later to all included patients.

\subsection{Questionnaire data}

The questionnaire was developed by a team of pain specialists, epidemiologists and family physicians according to other published questionnaires (Zigmond and Snaith, 1983; Von Korff et al., 1992; Vollenweider et al., 2006; Bouhassira et al., 2008). It was divided into five parts: sociodemographic data, assessment of pain characteristics and associated disability, mood disorder symptoms, patient's treatments and LOR to practise active self-care. Our questionnaire was mostly based on already published instruments: Chronic Pain Grade (Von Korff et al., 1992) and Hospital Anxiety and Depression Scale (Zigmond and Snaith, 1983; Bjelland et al., 2002). Understandability and interpretability of the questions were tested via cognitive testing (Beatty and Willis, 2007). The aim was to uncover how respondents interpreted the meaning of the questions, and whether or not these matched those of the investigators. Cognitive interviews have been conducted with ten chronic pain volunteer patients and with ten healthy volunteers, with different sociodemographic backgrounds. Questions have been rephrased when there was misconception to reduce response error.

\subsection{Pain characteristics}

Pain characteristics were assessed through pain frequency and localization with a body diagram as used in the brief pain inventory (Cleeland and Ryan, 1994). The presence of neuropathic characteristics of pain was assessed with the DN4 7-items questionnaire (Bouhassira et al., 2005, 2008), validated in French and largely used in clinical and research settings (Bouhassira et al., 2008, 2013; Attal et al., 2011). The cut-off value used was 3 or more positive answers, with a sensitivity and a specificity of $78 \%$ and $81.2 \%$, respectively, to confirm the presence of neuropathic pain (Bouhassira et al., 2005, 2008, 2013).

\subsection{Chronic Pain Grade questionnaire}

The pain status was assessed with the Chronic Pain Grade questionnaire, including pain ratings from 0 to
10, associated disability and average days unable to perform usual activities due to pain in the prior six months. It has been validated in the United States (Von Korff et al., 1992) and in the UK (Smith et al., 1997) and has been widely used in clinical research (Blyth et al., 2005; Raftery et al., 2011; Hauser et al., 2014). As no validated French version of this tool was available, the original version was translated, back-translated and pre-tested in a collaborative and iterative process according to WHO guidelines (WHO, 2015) and the Principles of Good Practise for the Translation and Cultural Adaptation Process for Patient-Reported Outcomes (PRO) Measures (Wild et al., 2005). To improve patients' understanding, a visual analogue scale was added to the original numeric rating scale (NRS). The Chronic Pain Grade questionnaire contains seven questions to grade the patients' pain intensity and disability from grade I (no pain, no disability) to grade IV (high disability, severely limiting) (Smith et al., 1997). Grading was calculated according to the method described by Von Korff (Von Korff et al., 1992). Pain intensity was classified in three groups according to the NRS rating: mild (1-3), moderate (4-6) and severe (7-10) (Bouhassira et al., 2008; Attal et al., 2011).

\subsection{Treatments used and LOR to practise active self-care}

Patients were asked whether they used nonopioid painkillers, opioids or dietary supplements 'against pain' during the last six months and if they had already used one of the following treatments against pain: interventional blocks, physical therapy, surgery, psychiatrist/psychologist follow-up, osteopathy, acupuncture, hypnosis, therapeutic massage or different self-care methods, as described below. The LOR to practise active self-care was assessed using a 0 to 10 scale also known as the 'Readiness Ruler', created and validated initially by Rollnick (Rollnick et al., 1992). A visual analogic readiness ruler combined with a 0-10 NRS with checkboxes and an anchor statement at the two extremities was designed as described by Miller and Rollnick (Miller, 2002) (see the questionnaire in the Appendix S2). The patients were asked to answer this following question for each specific therapy investigated: 'If your doctor would give you the option, what would be your level of readiness to practise this method as a complement of your pain treatment strategy? Please use the scale from 0 to 10,0 indicating "not at all ready" and 10 indicating "totally ready" to 
practise it'. Active self-care methods were classified in five categories: physical activity adapted to the pain condition and four other categories, defined according to (Delgado et al., 2014): physically oriented therapies (e.g. acupressure, self-administered therapeutic medical massage), movement therapies (e.g. yoga, tai chi, qi gong), mind-body therapies (e.g. self-hypnosis, autogenic training, meditation/ mindfulness, relaxation training, breathing exercises, imagery-guided therapy), and sensory art therapies (e.g. art therapy, dance therapy, music therapy). Categories of self-care were described in the questionnaire, as well as in the glossary added to the questionnaire on a coloured sheet, describing as precisely as possible the different therapies investigated in the questionnaire. This part was carefully tested during cognitive testing, especially with patients having never used any of these therapies. The LOR to practise active self-care as a complement of the pain treatment strategy was classified as low LOR (0-4 on the 0-10 NRS), moderate LOR (5-7) and high LOR (8-10) (Bertholet et al., 2012; Korcha et al., 2012). The perceived importance of and confidence in practicing each type of active self-care were also assessed, as these two other dimensions have been recognized to contribute to motivation building and have already been assessed in other studies about physical activity and lifestyle changes (Jensen et al., 2003; Rau et al., 2007; Bulc et al., 2015). Some other questionnaires have been developed to assess the motivation or the readiness to change, or to be involved in a treatment for chronic pain. For example, the Pain Stages of Change Questionnaire (PSOCQ) (Kerns et al., 1997), and the four versions of the Multidimensional Pain Readiness to Change Questionnaire (MPRCQ, MPRCQ2, MPRCQ2-13/26) (Nielson et al., $2008,2009)$. Because of the length of these questionnaires which could affect patient's willingness to participate to studies (Nielson et al., 2009) and because they were not suitable for investigating the different types of active self-care chosen in this study, we did not include them.

\subsection{Hospital Anxiety and Depression Scale}

The presence of anxiety or depression mood disorder was assessed with the Hospital Anxiety and Depression Scale (HADS) (Zigmond and Snaith, 1983; Bjelland et al., 2002). The score has been validated in French (Bocerean and Dupret, 2014) and is well recognized (Snaith, 2003). A cut-off value of 8 , with optimal specificity and sensitivity, was chosen to represent possible anxiety and depression (Zigmond and Snaith, 1983; Bjelland et al., 2002), and a score of 11 or higher indicated the probable presence of a mood disorder (Snaith, 2003). If there were two or more missing data points for each subscale, the scores were considered invalid, as suggested by Turk (Turk et al., 2015). Agreement to use the French version of the HADS questionnaire was obtained from Mapi Research Trust (France).

\subsection{Statistical methods}

As it was a descriptive and exploratory study, the sample size was calculated to ensure good precision for the estimation of the mean of the main outcome: the LOR to practise active self-care measured on a 0-10 scale. To obtain an estimate of an expected mean LOR of $6 \quad( \pm 6$ standard deviation (SD)) with a margin of error of $d=0.5$ (with $d$ corresponding to half of the confidence interval width when estimating the mean $(\mu)$ with $95 \%$ confidence), the required sample size was calculated as $n=4 *\left(\mathrm{sd}^{2}\right) / d^{2}=4 *(36) / 0.25=576$; therefore, a total of 576 responders was necessary. Given an expected response rate of approximately 50\% (Raftery et al., 2011; Bjornsdottir et al., 2014) and an estimation that $30 \%$ of our sample would no longer be suffering pain, the questionnaire was sent to 1640 participants to reach the target sample size.

Data quality and completeness (unusual values, consistency and missing values) were checked. Categorical data were summarized by frequencies and percentages, and continuous variables by their mean $( \pm \mathrm{SD})$ or median (interquartile range $(\mathrm{IQR}))$ when the normality assumption was violated. The LOR to practise active self-care for the different methods was coded in three categories: low [0-3], moderate [4-7] and high [8-10]. The associations between the explanatory factors (characteristics of pain, sociodemographic data, mood disorder symptoms) and the LOR were assessed using univariable multinomial logistic regression models. The strength of the association was measured by the relative risk ratio (RRR). Factors associated with the outcome at a level of $20 \%(p<0.20)$ were considered in a backward procedure to fit a multivariable model. We decided not to include the variables about previous experience with active self-care therapy, as we wanted to delineate other factors associated with the LOR. In addition, pairwise Pearson correlation coefficients between social activities, daily activities and working disability levels were calculated; Wilcoxon's 
matched-pairs signed-rank tests were performed to test the differences between these scores. The same analyses were performed to assess the correlations between the LOR to practise active self-care and the perceived importance of and confidence in practicing active self-care. We used statistical tests to support our exploratory analyses, not to confirm hypotheses developed a priori. Statistical analysis was performed using Stata 14 software (StataCorp 2015. Stata Statistical Software: Release 14. College Station, TX: StataCorp LP).

\subsection{Missing data}

Rates of missing data for variables used in the analyses are reported for all variables. Three items had a percentage of missing data higher than 5\%: body mass index (BMI), physical level of work and localization of chronic pain. For quality purposes, these variables were not used in the analysis as explanatory data.

\section{Results}

\subsection{Study samples}

Among the 1524 patients who received the questionnaire, $877(57.5 \%)$ returned it, and 639 (41.9\%) were finally included in the study. Details are shown in Fig. 1 .

\subsection{Sociodemographic data and working conditions}

Sociodemographic data are reported on Table 1. The mean age of respondents was 59.3 years old $(\mathrm{SD}=15.3)$. Two-thirds $(n=440,68.9 \%)$ of the respondents did not work because they were retired ( $n=238 / 440,52.7 \%)$ or could not due to a medical condition $(n=177 / 440,39.2 \%)$.

\subsection{Pain characteristics}

The characteristics of pain are described in Table 2 . The median (IQR) duration of pain was 8.5 (9.6) years. Most respondents suffered from constant pain $(n=400,62.6 \%)$ or at least once a day $(n=183$, $28.6 \%)$. Average \pm SD ratings on the 11 -points rating [0-10] scale for current, average, and worst pain were $5.6 \pm 2.3,6.1 \pm 2.0$ and $8.2 \pm 1.7$, respectively. The most frequent locations of pain were the middle or low back $(n=456,71.4 \%)$ and a lower limb $(n=437,68.4 \%)$, followed by pain in the cervical spine $(n=165,25.8 \%)$, an upper limb $(n=161,25.2 \%)$, or a shoulder $(n=147,23.0 \%)$. Neuropathic characteristics of pain were present in 327 patients $(51.2 \%)$.

Almost two-thirds ( $n=407,63.7 \%)$ of the respondents had high disability grades (Chronic Pain Grade: grade III and IV). Patients reported interferences in social activities (mean $=6.0, \mathrm{SD}=2.8)$, in daily activities $($ mean $=5.9, \quad \mathrm{SD}=2.7)$ and in working ability $($ mean $=5.8, \mathrm{SD}=3.1$ ). There was a correlation between disability during social vs daily activities $\left(\right.$ corr $\left._{\text {Pearson }}=0.672, p<0.01\right)$, during working vs daily activities $\left(\operatorname{corr}_{\text {Pearson }}=0.714, p<0.01\right)$ and during working vs social/recreational activities $\left(\operatorname{corr}_{\text {Pearson }}=0.778, p<0.01\right)$.

\subsection{Hospital Anxiety and Depression Scale}

Among the respondents, $37.2 \% \quad(n=238)$ had a probable mood disorder, and 25.5\% $(n=163)$ had a possible mood disorder. About a quarter had a probable depressive mood disorder $(n=166,26.0 \%)$, and $28.3 \%(n=181)$ had a probable anxious mood disorder.

\subsection{Use of healthcare resources}

During the last six months, 93.4\% $(n=597)$ of respondents had used painkillers, and $64.6 \%$ $(n=413)$ had used opioids. The use of dietary supplements 'against pain' was reported by $31.7 \%$ $(n=203)$ of respondents. The most common were magnesium, calcium and vitamins, followed by herbal medicine (e.g. Harpagophytum procumbens). The majority of patients $(n=527,82.5 \%)$ had received an interventional block at least once, as well as physical therapy $(n=499,78.1 \%)$. Among other methods, $48.4 \%(n=309)$ used therapeutic massage, $31.8 \% \quad(n=203) \quad$ osteopathy, $26.1 \% \quad(n=167)$ acupuncture, and $8.9 \%(n=57)$ hypnosis; $33.5 \%$ $(n=214)$ had consulted a psychiatrist or psychologist. The frequency of patients having already used active self-care was $57.0 \% \quad(n=364)$ for physical activity adapted for the pain condition, $29.1 \%$ $(n=186)$ for physically oriented therapies, $25.4 \%$ $(n=162)$ for mind-body therapies, $12.7 \%(n=81)$ for movement therapies and $10.3 \%(n=66)$ for sensory art therapies.

\subsection{LOR to practise active self-care methods when suggested by a physician}

A high or moderate LOR to practise active self-care was found in $44.1 \%(n=282)$ and in $24.6 \%$ 


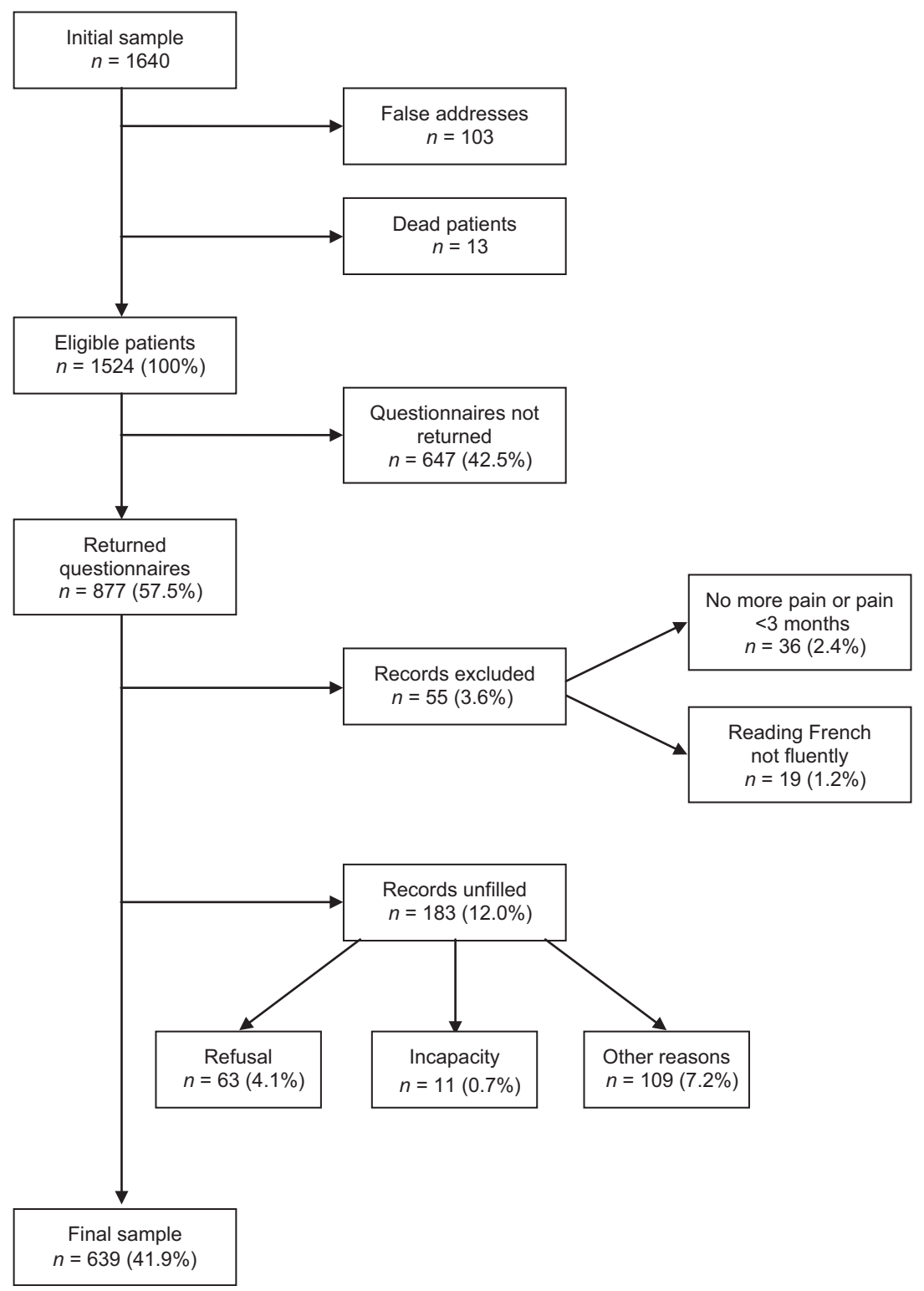

Figure 1 Flow diagram of the study.

$(n=157)$ of patients, respectively. The LOR was slightly higher for physical activity adapted for pain condition and physically oriented therapies (e.g. acupressure). The results are reported in Fig. 2.

The comparison of a low, moderate and high LOR to practise active self-care using univariate multinomial logistic regression analysis is described in Table 3. A high LOR to practise active self-care was associated with higher education levels, the presence of neuropathic characteristics, higher worst pain scores, higher disability in social and recreational activities and the use of dietary supplements. Older age, living alone and being unemployed were associated with a lower LOR to practise active self-care. Patients who had already used a self-care method had a higher LOR to practise active self-care, the highest association being for mind-body therapies, followed by sensory art therapies. The duration of pain, expressed in years, was not clinically different among the low (median $=5.0$, IQR: 7.5 ), moderate (median $=4.5$, IQR: 7.8) and high LOR groups (median $=5.0$, IQR: 9.0). Other pain characteristics (frequency, localization), chronic pain grade, the presence of anxiety or depression and the use of opoids did not influence the LOR to practise active self-care. 
Table 1 Sociodemographic data of the sample $(n=639)$.

\begin{tabular}{|c|c|c|}
\hline Variables & Groups & $n(\%)$ \\
\hline \multirow[t]{7}{*}{ Age (years) } & $<25$ & $8(1.3)$ \\
\hline & $25-34$ & $28(4.4)$ \\
\hline & $35-49$ & $128(20.0)$ \\
\hline & $50-64$ & $217(34.0)$ \\
\hline & $65-75$ & $144(22.6)$ \\
\hline & $>75$ & $103(16.1)$ \\
\hline & Missing & $11(1.7)$ \\
\hline \multirow[t]{3}{*}{ Gender } & Female & $355(55.6)$ \\
\hline & Male & $270(42.3)$ \\
\hline & Missing & $14(2.2)$ \\
\hline \multirow[t]{3}{*}{ Country of birth } & Switzerland & $390(61.0)$ \\
\hline & Other & 240 (37.6) \\
\hline & Missing & $9(1.4)$ \\
\hline \multirow[t]{5}{*}{ BMI } & Underweight $(<18.5)$ & $18(2.8)$ \\
\hline & Normal (18.5-24.9) & $234(36.6)$ \\
\hline & Overweight (25-29.9) & $177(27.7)$ \\
\hline & Obese $(\geq 30)$ & $140(21.9)$ \\
\hline & Missing & $70(11.0)$ \\
\hline \multirow[t]{6}{*}{ Living status } & Alone & $162(25.4)$ \\
\hline & Single with kids & $36(5.6)$ \\
\hline & Couple without kids & 238 (37.3) \\
\hline & Couple with kids & 149 (23.3) \\
\hline & With somebody & $43(6.7)$ \\
\hline & Missing & $11(1.7)$ \\
\hline \multirow[t]{4}{*}{ Education } & Basic & 189 (29.6) \\
\hline & Apprenticeship & 211 (33.0) \\
\hline & University/upper specialized school & $223(34.9)$ \\
\hline & Missing & $16(2.5)$ \\
\hline
\end{tabular}

The results are expressed as the number of participants (percentage), $n(\%)$. BMI: body mass index $\left(\mathrm{kg} / \mathrm{m}^{2}\right)$ was calculated using self-reported weight and height.

The comparison of a low, moderate and high LOR to practise active self-care using multivariate multinomial regression analysis is described in Table 4. Apprenticeship and university or upper specialized school education level $(\mathrm{RRR}=3.42$, 95\% CI: 1.90 6.13, $p<0.001)$, unemployment due to healthrelated conditions $(\mathrm{RRR}=2.92,95 \%$ CI: 1.30-6.56, $p=0.009)$, neuropathic pain characteristics $(\mathrm{RRR}=1.80,95 \% \mathrm{CI}: 1.04-3.12, p=0.036)$ and the use of dietary supplements $(\mathrm{RRR}=2.77,95 \% \mathrm{CI}$ : $1.52-5.04, p=0.001$ ) were factors that were independently associated with a high LOR. Older age was an independent negative factor associated with a high LOR $(\mathrm{RRR}=0.97,95 \%$ CI: 0.94-0.99, $p=0.039)$.

\subsection{Correlation between the readiness to practise self-care and the perceived importance of and confidence in practicing active self-care}

The strongest correlation among the three possible ways to evaluate the motivation of a patient to
Table 2 Characteristics of pain $(n=639)$.

\begin{tabular}{llc}
\hline Variables & Groups & $n(\%)$ \\
\hline Duration (years) & $<1$ & $24(3.8)$ \\
& $1-<3$ & $150(23.5)$ \\
& $3-<5$ & $134(21.0)$ \\
& $5-10$ & $132(20.7)$ \\
& $>10$ & $194(30.4)$ \\
Chronic pain grade & Missing & $5(0.8)$ \\
& Grade I & $59(9.2)$ \\
& Grade II & $160(25.0)$ \\
& Grade III & $162(25.4)$ \\
Current pain intensity & Grade IV & $245(38.3)$ \\
& Missing & $13(2.0)$ \\
& Mild (1-3) & $133(20.8)$ \\
& Moderate (4-6) & $257(40.2)$ \\
Average pain intensity & Severe (7-10) & $247(38.7)$ \\
& Missing & $2(0.3)$ \\
& Mild (1-3) & $58(9.1)$ \\
Worst pain intensity & Moderate (4-6) & $302(47.3)$ \\
& Severe (7-10) & $271(42.4)$ \\
& Missing & $76(1.3)$ \\
& Mild (1-3) & $550(86.1)$ \\
& Moderate (4-6) & $5(0.8)$ \\
\hline
\end{tabular}

The results are expressed as the number of participants and percentage: $n(\%)$.

practise active self-care was found between readiness and perceived importance $\left(\operatorname{corr}_{\text {Pearson }}=0.805\right.$, $p<0.001)$, followed by the correlations between perceived importance and confidence ( corr $\left._{\text {Pearson }}=0.785, p<0.001\right)$ and between readiness and confidence $\left(\operatorname{corr}_{\text {Pearson }}=0.727, p<0.001\right)$.

\section{Discussion}

In an academic medical centre, the majority of chronic pain patients were ready to try active self-care, as a half of them had a high LOR to practise active selfcare, and a quarter had a moderate LOR. Physical activity adapted to the pain condition exhibited the highest LOR, followed by physically oriented therapies, movement and mind-body therapies, and lastly sensory art therapies. Higher levels of education, unemployment due to health-related issues, the use of dietary supplements 'against pain' and neuropathic pain were associated with a higher LOR, while older age predicted a lower LOR. The LOR was not associated with the pain duration, high disability associated with pain or the presence of a mood disorder.

The chronic pain population of this study was comparable to those in the literature in terms of sex (higher female ratio) (Breivik et al., 2006; 


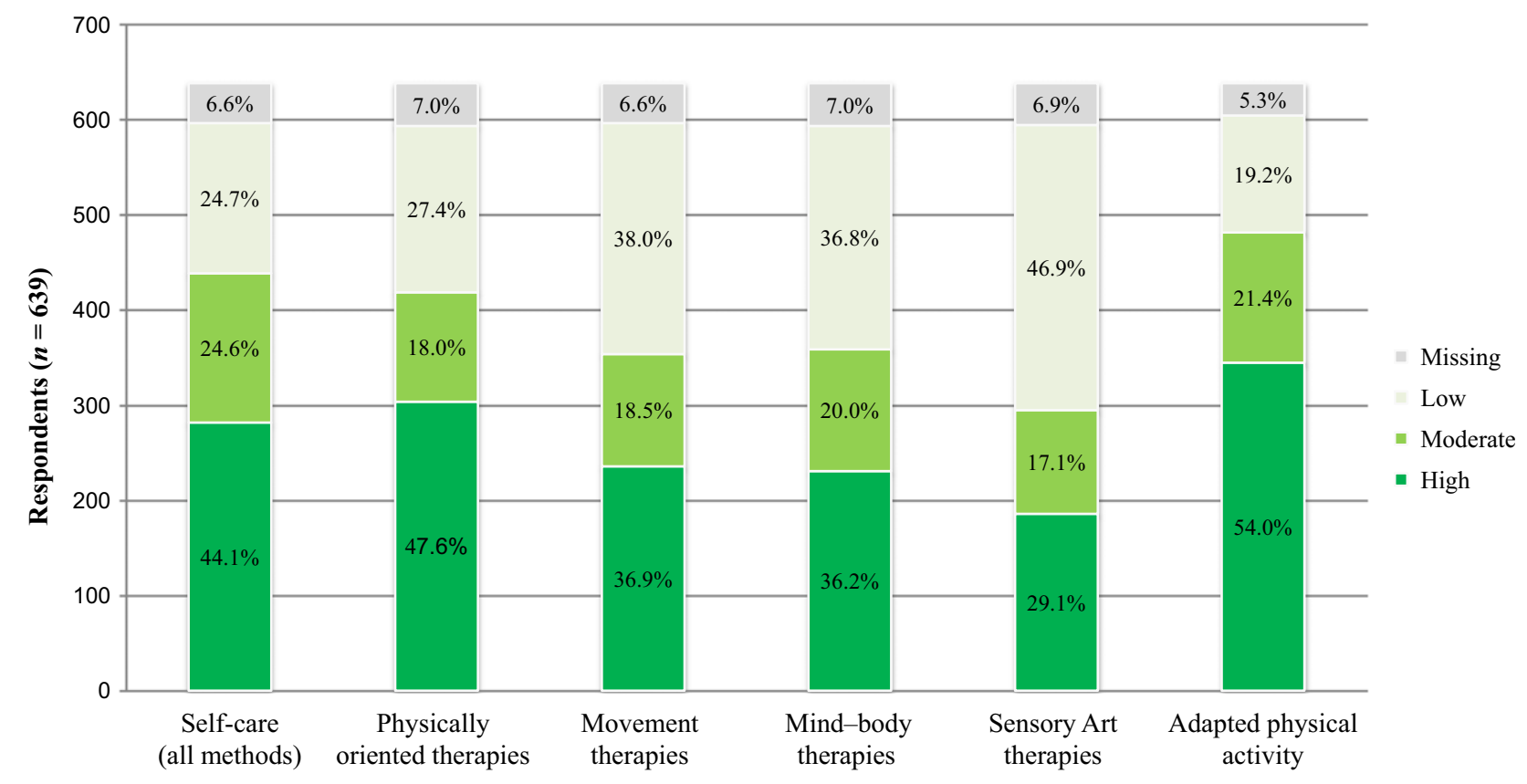

Methods of active self-care

Figure 2 The level of readiness of chronic pain patients to practise self-care methods. Groups defined according to the numeric rating scale from 0 to 10: low (0-3), moderate (4-7) and high (8-10). Physically oriented therapies (acupressure, self-administered therapeutic massage); movement therapies (yoga, tai chi, qi gong); mind-body therapies (self-hypnosis, meditation/mindfulness, relaxation training, imagery-guided therapy); sensory art therapies (art therapy, dance therapy, music therapy); adapted physical activity.

Bouhassira et al., 2008; Hardt et al., 2008; Gosden et al., 2014), BMI (most frequently normal or overweight) (Vaegter et al., 2014), mean age (Gosden et al., 2014; Campbell et al., 2015) and inactivity because of health issues. The most frequent locations of pain were the back and a lower limb, similar to the results of other studies in Europe and the United States (Breivik et al., 2006; Hardt et al., 2008; Kurita et al., 2012). As the aetiology of chronic pain was only self-reported by the patients, we decided not to analyse this data because there was a risk of an understanding bias. Only location and neuropathic pain characteristics (using the DN4-7 item) were taken into account.

The median pain duration was comparable to that of other chronic pain studies, mostly ranging from 3 to 10 years (Hauser et al., 2014; Vaegter et al., 2014). The $50 \%$ prevalence of neuropathic pain characteristics was higher than the $20 \%$ previously described in Denmark (Vaegter et al., 2014) and in France (Bouhassira et al., 2008). This difference could be linked with the higher referral rate of neuropathic pain patients to a tertiary (university) Pain Center. More than $60 \%$ of patients had a high disability associated with chronic pain, which was twice as high as previously reported values (Hauser et al.,
2014). Again, this might be explained by a selection bias of critical chronic pain patients referred to the Pain Center.

Two-thirds of the patients had used opioids, confirming the high prevalence of opioid use previously described in other countries among chronic pain patients (Kurita et al., 2012) (Weisner et al., 2009) (Edlund et al., 2014) (Dowell et al., 2016). The risks of major side effects, such as addiction, abuse or overdose (Edlund et al., 2014; Sutherland, 2014), as well as the increased risk of all-cause mortality (Ekholm et al., 2014), highlight the need to redirect treatment strategies to other pharmacological or nonpharmacological therapies (Mallen and Hay, 2015; Volkow and McLellan, 2016), while taking into account the patient as a whole, according to the biopsychosocial model of chronic pain.

The LOR to practise active self-care methods if suggested by a physician was high in our population of chronic pain patients. As this was the first study on the LOR to practise different types of active selfcare among chronic pain patients, a comparison with other studies was not possible. However, it was surprising to find that more than half of this population, considered to be poorly active and severely affected by pain, were prone to consider active self- 
Table 3 Comparison of low, moderate and high levels of readiness to practise self-care therapies among chronic pain patients using univariate logistic regression analysis.

\begin{tabular}{|c|c|c|c|}
\hline & $\begin{array}{l}\text { Low LOR N (\%) } \\
\text { or mean (SD) }\end{array}$ & $\begin{array}{l}\text { Moderate LOR } N(\%) \text { or mean (SD); } \\
\text { RRR }[95 \% \mathrm{Cl}], p\end{array}$ & $\begin{array}{l}\text { High LOR } N(\%) \text { or mean (SD); } \\
\text { RRR [95\% Cl], } p\end{array}$ \\
\hline \multicolumn{4}{|l|}{ Sociodemographic } \\
\hline Age (mean, SD) & $64.3(15.5)$ & 59.07 (15.3) $0.98[0.96-0.99], 0.002$ & 56.5 (14.3) $0.96[0.95-0.98],<0.001$ \\
\hline Sex male (ref=female) & $59(38.3)$ & 72 (47.1) 1.43 [0.91-2.25], 0.122 & $120(43.5) 1.24$ [0.83-1.85], 0.298 \\
\hline Country of birth (Swiss, ref=other) & $104(67.1)$ & 98 (63.6) 0.86 [0.54-1.37], 0.523 & $170(60.9) 0.77$ [0.51-1.16], 0.203 \\
\hline BMI (mean, SD) & $26.9(4.7)$ & 26.57 (6.1) 0.99 [0.94-1.03], 0.604 & 26.4 (4.8) 0.98 [0.94-1.02], 0.362 \\
\hline Living alone (ref=not living alone) & $47(30.1)$ & $46(29.9) 0.99$ [0.61-1.61], 0.960 & $58(20.9) 0.61$ [0.39-0.96], 0.033 \\
\hline \multicolumn{4}{|l|}{ Education } \\
\hline Basic & 61 (39.9); 1 (ref) & $45(29.2) 1$ (ref) & $66(23.8) 1$ (ref) \\
\hline Apprenticeship & $50(32.7)$ & $54(35.1) 1.46$ [0.85-2.52], 0.170 & $94(33.9) 1.74$ [1.07-2.83], 0.027 \\
\hline University/upper specialized school & $42(27.5)$ & 55 (35.7) 1.78 [1.02-3.10], 0.043 & $117(42.2) 2.58$ [1.57-4.23], <0.001 \\
\hline \multicolumn{4}{|l|}{ Employment } \\
\hline Unemployed (ref=with work) & $126(80.2)$ & $107(68.6) 0.54$ [0.32-0.90], 0.019 & $176(63.1) 0.420$ [0.27-0.67], <0.001 \\
\hline Unemployed due to health condition & $32(24.8)$ & 39 (35.1) 1.64 [0.94-2.87], 0.082 & 99 (54.4) 3.616 [2.21-5.93], <0.001 \\
\hline Pain's duration, years (median, IQR) & $7.9(7.5)$ & $8.2(7.8) 1.00$ [0.98-1.03], 0.774 & $9.2(9.0) 1.01$ [0.99-1.04], 0.203 \\
\hline \multicolumn{4}{|l|}{ Pain's frequency } \\
\hline Constant pain & 97 (61.8); 1 (ref) & 92 (58.6) 1 (ref) & 184 (65.3) 1 (ref) \\
\hline Pain at least once a day & 50 (31.9) & $47(29.9) 0.99$ [0.61-1.62], 0.971 & 76 (27.0) 0.80 [0.519-1.24], 0.316 \\
\hline Pain less frequent than daily & $10(6.4)$ & 18 (11.5) 1.90 [0.83-4.33], 0.127 & 22 (7.8) 1.16 [0.53-2.55], 0.712 \\
\hline $\begin{array}{l}\text { Pain with neuropathic } \\
\text { characteristics(ref=negative) }\end{array}$ & $62(40.8)$ & $80(54.1) 1.71$ [1.08-2.70], 0.022 & $171(60.9) 2.26$ [1.51-3.38], <0.001 \\
\hline \multicolumn{4}{|l|}{ Drug or dietary supplement use } \\
\hline Use of painkillers (ref=no use) & $153(96.8)$ & $142(91.0) 0.33[0.12-0.94], 0.039$ & $267(95.0) 0.62$ [0.22-1.76], 0.373 \\
\hline Use of opioids (ref=no use) & $102(69.9)$ & 95 (66.4) 0.85 [0.52-1.40], 0.532 & 190 (70.6) 1.04 [0.67-1.61], 0.870 \\
\hline Use of dietary supplements (ref=no use) & $37(23.7)$ & $43(28.3) 1.27$ [0.76-2.11], 0.361 & 116 (41.4) 2.28 [1.47-3.53], <0.001 \\
\hline \multicolumn{4}{|l|}{ Pain scores } \\
\hline Average pain score(mean, SD) & $6.2(2.1)$ & 6.2 (1.7) 1.01 [0.90-1.13], 0.934 & $6.1(2.0) 0.97$ [0.88-1.07], 0.542 \\
\hline Worst pain score (mean, SD) & $8.0(1.8)$ & $8.2(1.5) 1.09$ [0.95-1.24], 0.212 & 8.4 (1.6) 1.19 [1.06-1.34], 0.004 \\
\hline Current pain score (mean, SD) & $5.6(2.3)$ & 5.8 (2.0) 1.04 [0.94-1.15], 0.415 & $5.4(2.4) 0.96$ [0.88-1.05], 0.356 \\
\hline \multicolumn{4}{|l|}{ Disability } \\
\hline Disability in daily activities(mean, SD) & $5.7(2.8)$ & 5.9 (2.6) 1.03 [0.95-1.12], 0.461 & 6.2 (2.6) 1.07 [0.99-1.15], 0.070 \\
\hline $\begin{array}{l}\text { Disability in social or recreational } \\
\text { activities (mean, SD) }\end{array}$ & $5.6(2.9)$ & 5.9 (2.5) 1.04 [0.97-1.13], 0.292 & $6.3(2.9) 1.10$ [1.02-1.18], 0.009 \\
\hline Disability in work (mean, SD) & $5.1(3.1)$ & 5.7 (3.0) 1.05 [0.98-1.13], 0.154 & 6.2 (3.1) 1.11 [1.04-1.18], 0.001 \\
\hline \multicolumn{4}{|l|}{ Chronic pain grade } \\
\hline CPG I & $15(9.6)$ & $9(5.8)$ & $29(10.3)$ \\
\hline CPG ॥ & $46(29.3)$ & 47 (30.1) 1.70 [ 0.68-4.28], 0.257 & 63 (22.4) 0.71 [0.34-1.47], 0.355 \\
\hline CPG III & $42(26.8)$ & 46 (29.5) 1.83 [0.72-4.61], 0.203 & $64(22.8) 0.79$ [0.38-1.64], 0.526 \\
\hline CPG IV & $54(34.4)$ & $54(34.6) 1.67[0.67-4.13], 0.270$ & $125(44.5) 1.20$ [0.59-2.41], 0.614 \\
\hline \multicolumn{4}{|l|}{ Anxiety or depression disorder } \\
\hline $\begin{array}{l}\text { Probable anxiety disorder } \\
\text { (ref=absent/doubtful) }\end{array}$ & $42(27.5)$ & $45(29.0) 1.08$ [0.66-1.78], 0.758 & 85 (30.4) $1.15[0.74-1.78], 0.526$ \\
\hline $\begin{array}{l}\text { Probable depression } \\
\text { disorder (ref=absent/doubtful) }\end{array}$ & $38(24.5)$ & $45(29.0) 1.26$ [0.76-2.09], 0.370 & 75 (26.8) 1.13 [0.72-1.77], 0.605 \\
\hline \multicolumn{4}{|c|}{ Already used active self-care therapies (ref=not used) } \\
\hline Physically oriented therapies & $21(14.4)$ & $34(23.8) 1.86$ [1.02-3.39], 0.044 & $123(45.9) 5.05[3.00-8.50],<0.001$ \\
\hline Movements therapies & $8(5.5)$ & $21(14.5) 2.92$ [1.25-6.83], 0.013 & 49 (18.6) 3.93 [1.81-8.55], 0.001 \\
\hline Mind-body therapies & $14(9.7)$ & 36 (24.8) 3.09 [1.59-6.03], 0.001 & $104(39.1) 6.01$ [3.29-10.99], <0.001 \\
\hline Sensory art therapies & $5(3.5)$ & 13 (9.2) 2.82 [0.98-8.14], 0.055 & 46 (17.3) 5.86 [2.27-15.09], <0.001 \\
\hline Adapted physical activity & $66(44.6)$ & 85 (56.3) 1.60 [1.01-2.53], 0.044 & 197 (73.0) 3.35 [2.20-5.11], <0.001 \\
\hline
\end{tabular}

LOR, level of readiness. The results are expressed as the mean and standard deviation (SD) or frequency ( $N$ ) and per cent (\%), relative risk ratio (RRR) $[95 \% \mathrm{Cl}$ ], $p$ value (p). Significant data with a $p$ value less than 0.05 appear bold. Associations between the explanatory factors and the LOR were assessed using a univariable multinomial logistic regression model. 
Table 4 Comparison of low, moderate and high levels of readiness to practise self-care therapies among chronic pain patients using a multivariate multinomial logistic regression analysis.

\begin{tabular}{llll}
\hline Factors & Low LOR & Moderate LOR RRR [95\% Cl], $p$ & High LOR RRR [95\% Cl], $p$ \\
\hline Age & 1 (ref) & $\mathbf{0 . 9 7}[0.94-0.99], \mathbf{0 . 0 2 0}$ & $\mathbf{0 . 9 7}[0.94-0.99], \mathbf{0 . 0 3 9}$ \\
Apprenticeship, university or upper specialized school (ref: basic) & 1 (ref) & $\mathbf{2 . 4 8}[1.32-4.63], \mathbf{0 . 0 0 4}$ & $\mathbf{3 . 4 2}[1.90-6.13],<\mathbf{0 . 0 0 1}$ \\
Unemployed due to health condition (ref: employed) & 1 (ref) & 1.12 [0.47-2.67],0.800 & $\mathbf{2 . 9 2}[1.30-6.56], \mathbf{0 . 0 0 9}$ \\
Pain with neuropathic characteristics (ref: negative) & 1 (ref) & $\mathbf{2 . 0 2}[1.11-3.67], \mathbf{0 . 0 2 0}$ & $\mathbf{1 . 8 0}[1.04-3.12], \mathbf{0 . 0 3 6}$ \\
Use of dietary supplements (ref: no use) & 1 (ref) & $1.55[0.80-3.03], 0.197$ & $\mathbf{2 . 7 7}[1.52-5.04], \mathbf{0 . 0 0 1}$ \\
\hline
\end{tabular}

LOR, level of readiness. The results are expressed as the relative risk ratio (RRR) [95\% Cl], $p$ value $(p)$. Factors associated with the outcome at a level of $20 \%(p<0.20)$ in the univariable multinomial logistic regression were considered in a backward procedure to fit a multivariable model. Significant data with $p<0.05$ appear bold.

care. Moreover, the LOR was not associated with pain duration or with related disability or mood disorder, meaning that even patients with pain lasting for a very long period or with high disability were interested in active self-care.

A higher level of education has already been described as a factor increasing the use of therapies outside the field of conventional medicine, such as active self-care methods (Blyth et al., 2005) or complementary therapies (Eisenberg et al., 1998). The association between a low education level and a low LOR could be explained by a lack of knowledge of pain itself and available treatment strategies. Healthcare practitioners should help their patients to determine all potentially effective treatment options.

Patients exhibiting pain with neuropathic characteristics showed a higher LOR. As chronic pain patients with neuropathic characteristics showed a higher degree of related disability, such as lower quality of life, more sleep disturbance, anxiety and depression (Bouhassira et al., 2013), this might act as a 'trigger' to try every possible option to improve pain. While the use of painkillers did not influence the LOR in our study, the use of dietary supplements 'against pain' predicted a higher LOR.

As it was the first study about the LOR to practise different types of active self-care, we correlated the LOR with the perceived importance of and confidence in practicing self-care, as these two other indicators were already investigated in studies about motivation in health (Bertholet et al., 2012). There was a good correlation among these three parameters, meaning that the variable LOR could be a good tool for assessing patients' motivation. Considering the LOR of the patients to use one method of selfcare (or another treatment option) is crucial. Adapting the treatment strategy according to the patient's preference would probably improve the effectiveness of self-care; for example, this adaptation of treatment to the patient's preference has been shown to maximize the efficacy of integrative therapy in breast cancer (Carlson et al., 2014).

While studies on the effect of various self-care therapies for chronic pain are increasing, such as exercise (Chou et al., 2017), tai chi (Chou et al., 2017), yoga (Chou et al., 2017) and mindfulnessbased stress reduction (Cherkin et al., 2016; Chou et al., 2017), the strength of the evidence of effectiveness remains low or moderate (Chou et al., 2007; Rosenquist Richard, 2010; Wong et al., 2017). Even if a recent meta-analytic review 'found small but robust effects of guided self-help interventions for the treatment of chronic pain' (Liegl et al., 2016), more studies about the effectiveness of different types of active self-care are needed, notably to compare the different types of self-care therapies. Self-care methods that showed a higher LOR in this study should be studied first, as they would most likely be accepted by the majority of chronic pain patients.

\section{Limitations}

There are several limitations to this study. First, the investigation of the LOR as a reflection of the motivation to practise active self-care has not been performed by others. Although we used standardized questions used in other domains of motivation for change, we do not know whether the observed data on LOR demonstrate real readiness to do so even though there was a good correlation between LOR, importance and confidence. More studies are needed to confirm that LOR is correlated to motivation of the patient and may predict actual involvement in active self-care. Second, LOR is not a trait of the individual, as it is influenced by multiple aspects, especially beliefs concerning the pain itself and the treatment (degree of feasibility, perceived importance, confidence (or self-efficacy) and expectations) (Marcus et al., 1992; Keller et al., 2001; 
Jensen et al., 2003; Rau et al., 2007). Our study reflects endogenous motivation of the patients involved in the study at the time they were filling in the questionnaire, before any of these therapies have been really implemented by their physician in their pain treatment strategy. The level of readiness could surely evolve or be influenced by factors like the patient-provider interaction (Frantsve and Kerns, 2007) that were not investigated in this study. Third, the study was conducted in a single academic Pain Center, and the results could differ from those in other tertiary hospitals. The population of our study was also comparable to those of other studies on chronic patients regarding age, sex and BMI. Fourth, the study itself could have introduced a bias of answering by suggesting to patients that self-care options are valuable if investigated by a Pain Center. Meanwhile, no self-care therapy was offered at the time of the study, neither in the Pain Center nor in other areas of our hospital. Fifth, the definition of each therapy was based on the personal knowledge of each patient and on a lexicon integrated in the questionnaire. The results could have been influenced by a lack of exact knowledge of each therapy. Sixth, the response rate in our study $(41.9 \%)$ was in the low range of other postal surveys on pain among the general population (ranging from $40.1 \%$ to $60.7 \%$ ) (Hauser et al., 2014; Jakobsson and Larsson, 2014; Kurita et al., 2012; Landmark et al., 2013; Raftery et al., 2011; W. S. Wong and Fielding, 2011) but higher than another postal survey including patients from a Pain Center $(21 \%)$ (Gosden et al., 2014). This could have introduced a selection bias. Additionally, as patients had to fill the questionnaire in themselves, patients with a lower level of education, especially those with difficulty in reading French fluently, could be underrepresented in this study. Finally, the influence of catastrophizing, another aspect that has been shown to be correlated with poorer response to multidisciplinary pain treatments (Spinhoven et al., 2004), on patients' readiness for selfcare, was not evaluated.

\section{Conclusion}

Most chronic pain patients had a high or moderate LOR to practise active self-care methods if suggested by their physicians. Although the actual meaning and predictive ability of the LOR need to be assessed further, we found plausible results, such as an association of the LOR with a high level of education and neuropathic pain characteristics. The LOR was not lower for patients suffering from long-term chronic pain, high disability or mood disorders, suggesting that severely affected patients were also motivated to try active self-care. At a time of intense discussions about the benefits and risks of opioids, patients seem to be ready to try other treatment modalities. Active self-care therapies seem to be treatment options meriting further study for their impact on pain, mood disorders and quality of life, especially because patients do not seem reluctant to try them.

\section{Acknowledgements}

We thank Florence Degoumois for her advice during the preparation of the questionnaire. We also thank Magdalena Kosiba Becker for her assistance with administrative work.

\section{Ethics approval and consent to participate}

The protocol and the questionnaire were approved by the ethics committee of the Canton of Vaud. Informed consent was sought and granted.

\section{Availability of data and materials}

The data sets generated during this study are available from the corresponding author upon reasonable request.

\section{Author contributions}

E.S., I.D. and P.Y.R. conceived the study. E.S., I.D., B.B. and P.Y.R. developed the study design. E.S., I.D. and P.Y.R. oversaw the trial. E.S., B.B. and P.Y.R. drafted the manuscript. E.S., P.Y.R. and M.F. analysed the data. All authors have read and approved the final manuscript.

\section{References}

Ardern, C.L., Osterberg, A., Tagesson, S., Gauffin, H., Webster, K.E. Kvist, J. (2014). The impact of psychological readiness to return to sport and recreational activities after anterior cruciate ligament reconstruction. Br J Sports Med 48, 1613-1619.

Attal, N., Lanteri-Minet, M., Laurent, B., Fermanian, J., Bouhassira, D. (2011). The specific disease burden of neuropathic pain: results of a French nationwide survey. Pain 152, 2836-2843.

Baena-Beato, P.A., Arroyo-Morales, M., Delgado-Fernandez, M., GattoCardia, M.C., Artero, E.G. (2013). Effects of different frequencies (23 days/week) of aquatic therapy program in adults with chronic low back pain. A non-randomized comparison trial. Pain Med 14, 145158.

Barlow, J., Wright, C., Sheasby, J., Turner, A., Hainsworth, J. (2002). Self-management approaches for people with chronic conditions: a review. Patient Educ Couns 48, 177-187. 
Beatty, P.C., Willis, G.B. (2007). Research synthesis: the practice of cognitive interviewing. Public Opin Q 71, 287-311.

Bertholet, N., Gaume, J., Faouzi, M., Gmel, G., Daeppen, J.B. (2012). Predictive value of readiness, importance, and confidence in ability to change drinking and smoking. BMC Public Health 12, 708.

Bjelland, I., Dahl, A.A., Haug, T.T., Neckelmann, D. (2002). The validity of the hospital anxiety and depression scale. an updated literature review. J Psychosom Res 52, 69-77.

Bjornsdottir, S.V., Jonsson, S.H., Valdimarsdottir, U.A. (2014). Mental health indicators and quality of life among individuals with musculoskeletal chronic pain: a nationwide study in Iceland. Scand $J$ Rheumatol 43, 419-423.

Blyth, F.M., March, L.M., Nicholas, M.K., Cousins, M.J. (2005). Selfmanagement of chronic pain: a population-based study. Pain 113, 285-292.

Bocerean, C., Dupret, E. (2014). A validation study of the Hospital Anxiety and Depression Scale (HADS) in a large sample of French employees. BMC Psychiatry 14, 354.

Bouhassira, D., Attal, N., Alchaar, H., Boureau, F., Brochet, B. et al. (2005). Comparison of pain syndromes associated with nervous or somatic lesions and development of a new neuropathic pain diagnostic questionnaire (DN4). Pain 114, 29-36.

Bouhassira, D., Lanteri-Minet, M., Attal, N., Laurent, B., Touboul, C. (2008). Prevalence of chronic pain with neuropathic characteristics in the general population. Pain 136, 380-387.

Bouhassira, D., Letanoux, M., Hartemann, A. (2013). Chronic pain with neuropathic characteristics in diabetic patients: a French crosssectional study. PLOS ONE 8, e74195.

Boyers, D., McNamee, P., Clarke, A., Jones, D., Martin, D., Schofield, P., Smith, B.H. (2013). Cost-effectiveness of self-management methods for the treatment of chronic pain in an aging adult population: a systematic review of the literature. Clin J Pain 29, 366375.

Breivik, H., Collett, B., Ventafridda, V., Cohen, R., Gallacher, D. (2006). Survey of chronic pain in Europe: prevalence, impact on daily life, and treatment. Eur J Pain 10, 287-333.

Bulc, M., Svab, I., Godycki-Cwirko, M. (2015). Factors that affect readiness to change lifestyle: A 22-country survey from primary care. Eur J Gen Pract 21, 33-38.

Busch, A.J., Barber, K.A., Overend, T.J., Peloso, P.M., Schachter, C.L. (2007).Exercise for treating fibromyalgia syndrome. Cochrane Database Syst Rev 17943797, Cd003786.

Campbell, G., Nielsen, S., Bruno, R., Lintzeris, N., Cohen, M. et al. (2015). The Pain and Opioids IN Treatment study: characteristics of a cohort using opioids to manage chronic non-cancer pain. Pain 156, $231-242$.

Carlson, L.E., Tamagawa, R., Stephen, J., Doll, R., Faris, P., Dirkse, D., Speca, M. (2014). Tailoring mind-body therapies to individual needs: patients' program preference and psychological traits as moderators of the effects of mindfulness-based cancer recovery and supportiveexpressive therapy in distressed breast cancer survivors. JNCI Monogr 2014, 308-314.

Cherkin, D.C., Sherman, K.J., Balderson, B.H., Cook, A.J., Anderson, M.L. et al. (2016). Effect of mindfulness-based stress reduction vs cognitive behavioral therapy or usual care on back pain and functional limitations in adults with chronic low back pain: a randomized clinical trial. JAMA 315, 1240-1249.

Chou, R., Qaseem, A., Snow, V., Casey, D., Cross, J. T. et al. (2007). Diagnosis and treatment of low back pain: a joint clinical practice guideline from the American College of Physicians and the American Pain Society. Ann Intern Med 147, 478-491.

Chou, R., Deyo, R., Friedly, J., Skelly, A., Hashimoto, R. et al. (2017). Nonpharmacologic therapies for low back pain: a systematic review for an American College of Physicians Clinical Practice Guideline. Ann Intern Med 166, 493-505.

Cleeland, C.S., Ryan, K.M. (1994). Pain assessment: global use of the brief pain inventory. Ann Acad Med Singapore 23, 129-138.

Crawford, C., Lee, C., Buckenmaier, C. 3rd, Schoomaker, E., Petri, R., Jonas, W., Active Self-Care Therapies for Pain Working, G (2014a). The current state of the science for active self-care complementary and integrative medicine therapies in the management of chronic pain symptoms: lessons learned, directions for the future. Pain Med 15(Suppl 1), S104-S113.

Crawford, C., Lee, C., Freilich, D., Active Self-Care Therapies for Pain Working, G (2014b). Effectiveness of active self-care complementary and integrative medicine therapies: options for the management of chronic pain symptoms. Pain Med 15(Suppl 1), S86-S95.

Delgado, R., York, A., Lee, C., Crawford, C., Buckenmaier, C. 3rd et al. (2014). Assessing the quality, efficacy, and effectiveness of the current evidence base of active self-care complementary and integrative medicine therapies for the management of chronic pain: a rapid evidence assessment of the literature. Pain Med 15(Suppl 1), S9-S20.

Dobson, J.L., McMillan, J., Li, L. (2014). Benefits of exercise intervention in reducing neuropathic pain. Front Cell Neurosci 8, 102.

Dorflinger, L., Kerns, R.D., Auerbach, S.M. (2013). Providers' roles in enhancing patients' adherence to pain self management. Transl Behav Med 3, 39-46.

Dowell, D., Haegerich, T.M., Chou, R. (2016). CDC guideline for prescribing opioids for chronic pain-United States, 2016. JAMA 315 1624

Edlund, M.J., Austen, M.A., Sullivan, M.D., Martin, B.C., Williams, J.S., Fortney, J.C., Hudson, T.J. (2014). Patterns of opioid use for chronic noncancer pain in the Veterans Health Administration from 2009 to 2011. Pain 155, 2337-2343.

Eisenberg, D.M., Davis, R.B., Ettner, S.L., Appel, S., Wilkey, S., Van Rompay, M., Kessler, R.C. (1998). Trends in alternative medicine use in the United States, 1990-1997: results of a follow-up national survey. JAMA 280, 1569-1575.

Ekholm, O., Kurita, G.P., Hojsted, J., Juel, K., Sjogren, P. (2014). Chronic pain, opioid prescriptions, and mortality in Denmark: a population-based cohort study. Pain 155, 2486-2490.

Elliott, A.M., Smith, B.H., Hannaford, P.C., Smith, W.C., Chambers, W.A. (2002). The course of chronic pain in the community: results of a 4-year follow-up study. Pain 99, 299-307.

Falk, M., Anderson, C.D. (2013). Influence of age, gender, educational level and self-estimation of skin type on sun exposure habits and readiness to increase sun protection. Cancer Epidemiol 37, 127-132.

Frantsve, L.M., Kerns, R.D. (2007). Patient-provider interactions in the management of chronic pain: current findings within the context of shared medical decision making. Pain Med 8, 25-35.

Gosden, T., Morris, P.G., Ferreira, N.B., Grady, C., Gillanders, D.T. (2014). Mental imagery in chronic pain: prevalence and characteristics. Eur J Pain 18, 721-728.

Habib, S., Morrissey, S., Helmes, E. (2005). Preparing for pain management: a pilot study to enhance engagement. J Pain 6, 48-54.

Hardt, J., Jacobsen, C., Goldberg, J., Nickel, R., Buchwald, D. (2008). Prevalence of chronic pain in a representative sample in the United States. Pain Med 9, 803-812.

Hauser, W., Schmutzer, G., Hilbert, A., Brahler, E., Henningsen, P. (2014). Prevalence of chronic disabling non - cancer pain and associated demographic and medical variables: a cross-sectional survey in the general German population. Clin J Pain 31, 886-892.

Hayden, J.A., van Tulder, M.W., Malmivaara, A.V., Koes, B.W. (2005). Meta-analysis: exercise therapy for nonspecific low back pain. Ann Intern Med 142, 765-775.

Heneweer, H., Vanhees, L., Picavet, H.S. (2009). Physical activity and low back pain: a U-shaped relation? Pain 143, 21-25.

IASP (I. A. f. t. S. o. P.) (1986). Classification of chronic pain. Descriptions of chronic pain syndromes and definitions of pain terms. Pain, (Suppl 3), S1-S226.

Jakobsson, U., Larsson, C. (2014). Smoking and chronic pain among people aged 65 years and older. Pain Pract 14, 237-244.

Jensen, M.P., Nielson, W.R., Turner, J.A., Romano, J.M., Hill, M.L. (2003). Readiness to self-manage pain is associated with coping and with psychological and physical functioning among patients with chronic pain. Pain 104, 529-537.

Jensen, M.P., Nielson, W.R., Turner, J.A., Romano, J.M., Hill, M.L. (2004). Changes in readiness to self-manage pain are associated with 
improvement in multidisciplinary pain treatment and pain coping. Pain 111, 84-95.

Keller, S., Herda, C., Ridder, K., Basler, H.D. (2001). Readiness to adopt adequate postural habits: an application of the transtheoretical model in the context of back pain prevention. Patient Educ Couns 42, 175-184.

Kerns, R.D., Rosenberg, R., Jamison, R.N., Caudill, M.A., Haythornthwaite, J. (1997). Readiness to adopt a self-management approach to chronic pain: the Pain Stages of Change Questionnaire (PSOCQ). Pain 72, 227-234.

Korcha, R.A., Cherpitel, C.J., Moskalewicz, J., Swiatkiewicz, G., Bond, J., Ye, Y. (2012). Readiness to change, drinking, and negative consequences among Polish SBIRT patients. Addict Behav 37, 287-292.

Kurita, G.P., Sjogren, P., Juel, K., Hojsted, J., Ekholm, O. (2012). The burden of chronic pain: a cross-sectional survey focussing on diseases, immigration, and opioid use. Pain 153, 2332-2338.

Landmark, T., Romundstad, P.R., Borchgrevink, P.C., Kaasa, S., Dale, O. (2013). Longitudinal associations between exercise and pain in the general population-the HUNT pain study. PLOS ONE 8, e65279.

Liegl, G., Boeckle, M., Leitner, A., Pieh, C. (2016). A meta-analytic review of brief guided self-help education for chronic pain. Eur J Pain 20, 1551-1562.

MacFarlane, G.J., Thomas, E., Papageorgiou, A.C., Schollum, J., Croft, P.R., Silman, A.J. (1996). The natural history of chronic pain in the community: a better prognosis than in the clinic? J Rheumatol 23 , 1617-1620.

Mallen, C., Hay, E. (2015). Managing back pain and osteoarthritis without paracetamol. BMJ 350, h1352.

Marcus, B.H., Rakowski, W., Rossi, J.S. (1992). Assessing motivational readiness and decision making for exercise. Health Psychol 11, 257261.

Miller, W.R.R.S. (2002). Motivational Interviewing: Preparing People for Change, 2nd edn (New York: Guilford).

Nielson, W.R., Jensen, M.P., Ehde, D.M., Kerns, R.D., Molton, I.R (2008). Further development of the multidimensional pain readiness to change questionnaire: the MPRCQ2. J Pain 9, 552-565.

Nielson, W.R., Armstrong, J.M., Jensen, M.P., Kerns, R.D. (2009). Two brief versions of the multidimensional pain readiness to change questionnaire, version 2 (MPRCQ2). Clin J Pain 25, 48-57.

Prochaska, J.O., DiClemente, C.C., Norcross, J.C. (1992). In search of how people change. Applications to addictive behaviors. Am Psychol 47, 1102-1114.

Raftery, M.N., Sarma, K., Murphy, A.W., De la Harpe, D., Normand, C., McGuire, B.E. (2011). Chronic pain in the Republic of Irelandcommunity prevalence, psychosocial profile and predictors of painrelated disability: results from the Prevalence, Impact and Cost of Chronic Pain (PRIME) study, part 1. Pain 152, 1096-1103.

Rau, J., Ehlebracht-Konig, I., Petermann, F. (2007). Impact of readiness to change of the transtheoretical model (TTM) for the course of coping with chronic pain. Schmerz 21, 522-528

Rollnick, S., Heather, N., Gold, R., Hall, W. (1992). Development of a short 'readiness to change' questionnaire for use in brief, opportunistic interventions among excessive drinkers. Br J Addict 87, 743-754.

Rosenquist Richard, W. (A. S. o. A. T. F. o. c. p. M) (2010). Practice guidelines for chronic pain management. Anesthesiology 112, 1-24.

Shutty, M.S. Jr, DeGood, D.E., Tuttle, D.H. (1990). Chronic pain patients' beliefs about their pain and treatment outcomes. Arch Phys Med Rehabil 71, 128-132.

Smith, B.H., Penny, K.I., Purves, A.M., Munro, C., Wilson, B. et al (1997). The Chronic Pain Grade questionnaire: validation and reliability in postal research. Pain 71, 141-147.

Snaith, R.P. (2003). The hospital anxiety and depression scale. Health Qual Life Outcomes 1, 29.
Spinhoven, P., Ter Kuile, M. Kole-Snijders, A.M., Hutten Mansfeld, M., Den Ouden, D.J., Vlaeyen, J.W. (2004). Catastrophizing and internal pain control as mediators of outcome in the multidisciplinary treatment of chronic low back pain. Eur J Pain 8, 211-219.

Sutherland, S. (2014). Pain that won't quit. ScientificAmerican.com, December 2014, 61-68.

Turk, D.C., Wilson, H.D., Cahana, A. (2011). Treatment of chronic noncancer pain. Lancet 377, 2226-2235.

Turk, D.C., Dworkin, R.H., Trudeau, J.J., Benson, C., Biondi, D.M., Katz N.P., Kim, M. (2015). Validation of the hospital anxiety and depression scale (HADS) in patients with acute low back pain. J Pain 13, S24.

Uthman, O.A., van der Windt, D.A., Jordan, J.L., Dziedzic, K.S., Healey, E.L., Peat, G.M., Foster, N.E. (2013). Exercise for lower limb osteoarthritis: systematic review incorporating trial sequential analysis and network meta-analysis. BMJ 347, f5555.

Vaegter, H.B., Andersen, P.G., Madsen, M.F., Handberg, G., Enggaard, T.P. (2014). Prevalence of neuropathic pain according to the IASP grading system in patients with chronic non-malignant pain. Pain Med 15, 120-127.

Volkow, N.D., McLellan, A.T. (2016). Opioid abuse in chronic painmisconceptions and mitigation strategies. $N$ Engl J Med 374, 12531263

Vollenweider, P., Hayoz, D., Preisig, M., Pecoud, A., Warterworht, D. et al. (2006). Health examination survey of the Lausanne population: firs results of the CoLaus study. Rev Med Suisse 2, 2528-2530, 2532-2523.

Von Korff, M., Ormel, J., Keefe, F.J., Dworkin, S.F. (1992). Grading the severity of chronic pain. Pain 50, 133-149.

Weisner, C.M., Campbell, C.I., Ray, G.T., Saunders, K., Merrill, J.O. et al. (2009). Trends in prescribed opioid therapy for non-cancer pain for individuals with prior substance use disorders. Pain 145, 287-293.

WHO (2015). http://www.who.int/substance_abuse/research_tools/tra nslation/en/.In

Wild, D., Grove, A., Martin, M., Eremenco, S., McElroy, S. et al. (2005). Principles of good practice for the translation and cultural adaptation process for patient-reported outcomes (PRO) measures: report of the ISPOR task force for translation and cultural adaptation. Value Health 8, 94-104.

Wong, W.S., Fielding, R. (2011). Prevalence and characteristics of chronic pain in the general population of Hong Kong. J Pain 12 236-245.

Wong, J.J., Cote, P., Sutton, D.A., Randhawa, K., Yu, H. et al. (2017). Clinical practice guidelines for the noninvasive management of low back pain: a systematic review by the Ontario protocol for traffic injury management (OPTIMa) collaboration. Eur J Pain 21, 201-216.

Zigmond, A.S., Snaith, R.P. (1983). The hospital anxiety and depression scale. Acta Psychiatr Scand 67, 361-370.

\section{Supporting Information}

Additional supporting information may be found online in the Supporting Information section at the end of the article.

Appendix S1 Enquête auprès des patients sur leur douleur chronique et leur motivation à pratiquer de l'autosoin comme complément au traitement.

Appendix S2 Lexique des méthodes de traitement apparaissant dans le questionnaire. 